\title{
Correction to: ONE SHOT - single shot radiotherapy for localized prostate cancer: study protocol of a single arm, multicenter phase I/II trial
}

Thomas Zilli, ${ }^{1,2}$, Marta Scorsetti ${ }^{3,4}$, Daniel Zwahlen ${ }^{5}$, Ciro Franzese ${ }^{4}$, Robert Förster ${ }^{6}$, Niccolò Giaj-Levra ${ }^{7}$, Nikolaos Koutsouvelis ${ }^{1}$, Aurelie Bertaut ${ }^{8}$, Michel Zimmermann ${ }^{5}$, Giuseppe Roberto D'Agostino ${ }^{4}$, Filippo Alongi ${ }^{7,9}$, Matthias Guckenberger ${ }^{6}$ and Raymond Miralbell ${ }^{1,2}$

\section{Correction}

Following publication of the original article [1], the authors reported that one of the authors' names is spelled incorrectly. In this Correction the incorrect and correct author name are shown. The original publication of this article has been corrected.

Originally the author name has been published as:

- Nikolaos Koustouvelis

The correct author name is:

- Nikolaos Koutsouvelis

\section{Author details}

'Radiation Oncology, Geneva University Hospital, CH-1211, 14 Geneva, Switzerland. ${ }^{2}$ Faculty of Medicine, Geneva University, Geneva, Switzerland. ${ }^{3}$ Radiation Oncology, Humanitas University, Rozzano, Milan, Italy. ${ }^{4}$ Radiation Oncology, Humanitas Research Hospital and Cancer Center, Rozzano, Milan, Italy. ${ }^{5}$ Radiation Oncology, Kantonsspital Graubünden, Chur, Switzerland. ${ }^{6}$ Radiation Oncology, University Hospital Zürich, Zürich, Switzerland. 'Radiation Oncology, Sacro Cuore Don-Calabria, Negrar, Italy. ${ }^{8}$ Methodology and biostatistic unit, Centre Georges François Leclerc, Dijon, France. ${ }^{9}$ Faculty of Medecine, University of Brescia, Brescia, Italy.

Received: 13 September 2018 Accepted: 13 September 2018 Published online: 19 September 2018

\section{Reference}

1. Zilli, et al. Radiat Oncol. 2018;13(166). https://doi.org/10.1186/s13014-018-1112-0.

\footnotetext{
*Correspondence: Thomas.Zilli@hcuge.ch; Thomas.Zilli@unige.ch

${ }^{1}$ Radiation Oncology, Geneva University Hospital, CH-1211, 14 Geneva, Switzerland

${ }^{2}$ Faculty of Medicine, Geneva University, Geneva, Switzerland

Full list of author information is available at the end of the article
}

(c) The Author(s). 2018 Open Access This article is distributed under the terms of the Creative Commons Attribution 4.0 International License (http://creativecommons.org/licenses/by/4.0/), which permits unrestricted use, distribution, and reproduction in any medium, provided you give appropriate credit to the original author(s) and the source, provide a link to the Creative Commons license, and indicate if changes were made. The Creative Commons Public Domain Dedication waiver (http://creativecommons.org/publicdomain/zero/1.0/) applies to the data made available in this article, unless otherwise stated. 